\title{
Asymmetrical Reciprocity in Intergenerational Justice
}

Just World Institute, Edinburgh University, October 2010

Matthias Fritsch, Concordia University Montréal/Goethe Universität Frankfurt

\section{Introduction}

The concepts of sustainability that are most widely accepted in the international arena are underwritten not only by duties to contemporaries, but also, and crucially, by duties to non-overlapping generations. But what, if anything, grounds this long-term responsibility? I argue that generational connectedness, or intergenerational dependence, suggest that such responsibility is grounded in a form of reciprocity that is often called indirect but that I call, for reasons that will emerge shortly, asymmetrical. The basic claim of intergenerational reciprocity is that we must take responsibility for the well being of the next and then also non-overlapping generations because we are indebted to the previous and thereby also yet earlier, even historically distant generations. We owe our predecessors the material (socio-economic wealth and institutions) and symbolic (cultural, normative, and linguistic) goods without which we could not be who we are and do what it seems we like to do.

Seeking to propose intergenerational reciprocity, I will begin with elaborating and refining some of its features, so as to then highlight its strengths. Throughout, the core argument is that social life cannot be adequately grasped without its pointing to a time before me and a time after me: each of us was born of the gifts of others and will leave life to yet other others. Time connects us across birth and death, but it also separates us, putting each on his or her own journey between birth and death. Precisely because time is not merely shared (not even among contemporaries) but discontinuously recommences in each person, social cooperation and democratic life consist in a taking turns that is most obviously theorized as indirect reciprocity. 


\section{Feminist Criticisms of Reciprocity}

One useful starting point for developing justice as reciprocity into an intergenerational theory is the feminist literature on reciprocity theories (whether contractualist or contractarian). Except to the extent that it will lead to highlighting some crucial features of intergenerational justice, however, I will not discuss the significance of reciprocity in general, that is, its intimate connection with some basic and widely accepted principles of fair play (McLean Parks 1997; Klosko 1989, Rawls 1971) and its centrality to social cooperation and social life, even if we concentrate only on the living (Levi-Strauss 1949; Ekeh 1974; Becker 1986; Gintis 2000). Instead I will focus on what may be said to recommend reciprocity in the intergenerational setting, particularly the indirect kind. As we will see, the attractive features of the reciprocity-model, as I see it, are linked to the fact that it does justice to intergenerational relations in both temporal directions, the past and the future.

Justice as reciprocity, understood as mutual advantage or fair play, from Gauthier to Rawls, has often been accused, in particular by feminist authors, of mistakenly assuming "rough equality" as a starting point, as if justice was a matter of bargaining between parties of equal power (Nussbaum 2001; 2006). Indeed, many theories of justice in this tradition begin by seeking to establish this equality in the face of actual inequalities, by arguing that the weaker parties are still a threat to the stronger one (Hobbes famously argued that the weak can kill the strong in their sleep; see Becker 2005). This, the objection goes, neglects or even ignores the reality of interpersonal dependency and the need for care that characterizes human relations, e.g. in relation to childhood, parenting, old age, sickness, and disability (Held 1995; Kittay 1999, cf. Menke 2002)—care that is predominantly carried out by women. Agreeing with these criticisms ${ }^{1}$ I also think that the intergenerational dimension of taking caring for dependent others deserves further exploration.

The closest approximation to it may be in Eva Kittay's friendly amendment to Rawls's reciprocity-based model of social cooperation, an amendment that seeks to correct the "rough equality" Rawls assumes by having the parties in the original position think of themselves as in need of dependent care as well. After developing an indirect model of reciprocity she calls 'doulia', Kittay most helpfully points to, but does not elaborate-let alone for purposes of developing an account of intergenerational justice - the intergenerational significance of including the mother-infant relation as paradigmatic for justice relations:

Since society is an association that persists through generations, an extended notion of "reciprocity" (a transitive—if you will—responsiveness 
to our dependence on others) is needed for justice between

generations...just as the savings and gains from a previous generation pass from us to the next generation, the care a mother bestows on her child calls for reciprocation from the adult child not only back to the parents, but also forward to a future generation (Kittay 1999: 107).

In speaking of asymmetrical reciprocity, I seek to combine Kittay's "extended" (or indirect, and for her Rawlsian) reciprocity with the (non-Rawlsian) asymmetry that she here stresses in the mother-infant relation. If we do not, as the social contract tradition is wont to do, take rough equality (of strategic or communicative actors) as a starting point, then the paradigmatic case will be one of an asymmetrical relation between the one called to responsibility and the object of moral concern-a relation that need not be restricted to parents and their offspring, but may be seen as including all those cases in which one person takes asymmetrical responsibility for another who may survive her.

The intergenerational dimension of responsible agency in general lies in the fact that each agent has been cared for by (and more generally benefited from) others who precede him or her, and will be survived (exceeded) by yet others who may care for her or him in old age, and who care for the next generation. Responsibility thus points to a time before birth and after death. Sociality in general, and responsible agency in particular, can hardly be understood without taking this temporality, the generativity as well as mortality of life, into account. Arguably, indirect intergenerational reciprocity is best placed to recognize this intergenerational temporality, the connectedness of human life across birth and death in what is both a continuity and a discontinuity. For in arguing that we owe our descendants because we received from our predecessors, indirect reciprocity is perhaps the only approach to intergenerational justice that takes both the past and the future into account in the very grounding of the obligation. Obligation responds to a past donation that claims the present to take responsibility for the future.

Now let us flesh out this core idea a bit further.

\section{Indirect, Generalized, and Asymmetrical Reciprocity}

The (asymmetrical) reciprocity proposed here is characterized by three features: (i) it is indirect, (ii) generalized, and (iii) asymmetrical. 
(i) To say it is indirect is to say that a recipient of benefits need not, and in some cases definitely will not, discharge his obligations (for the most part) to the original donor, but to a third party. The obligation is not, or not only, direct in being generated by its object; rather, the obligation is indirect, generated by a previous interaction in which the object of the obligation, the recipient of benefits, need not have been involved. The obligation involves a kind of 'paying forward' (to cite a movie title): $A$ gives to $B$ and $B$ gives back to $C$.

The extant literature on intergenerational reciprocity distinguishes different models, among other things, by the direction of giving and thus by the direct or the indirect nature of the reciprocity. In a most helpful account, Gosseries (in Gosseries and Meyer 2009) speaks of descending, ascending, and double models concerning the question both of justification (why we owe) and of the substantive one of determining the content of the obligation (what is owed). On the descending model, the most commonly intuited one, the current generation owes to the future because it received from the past, and it owes at least as much as it received. On the ascending model, underlying for instance pay-as-you go pension schemes, the present generation owes to the preceding (but still overlapping) generation because that generation also discharged its obligation to its predecessors. For example, currently employed individuals, one may argue, should pay for their parents' pensions because their parents, at the time when they were still actively working, did the same for their own parents. Double reciprocity combines both descending and ascending models by arguing, to stay with the example, that the currently active generation should pay for their parents' retirement income because of what the parents did for this current generation when they were children and young adults (e.g., paying for their education).

Of these three intergenerational models of reciprocity, only the 'double' model is said to be direct whereas the 'descending' one as well as the 'ascending' one are indirect: here, donor and recipient are not the same. Although human sociality involves all three types of reciprocities and the notion of asymmetrical reciprocity should make room for caring for old age as well, the model I propose here focuses on the descending variety: the living generation receives benefits from preceding ones but owes to succeeding generations. ${ }^{2}$

We should pay close attention to what happens when we allow reciprocity to generate obligations indirectly. In general, justice as reciprocity argues that an agent should reciprocate either because of what happened in the past or what will or may happen in the future. In the first case, there is an obligation to reciprocate as (1a) the agent already benefited, or (1b) could have benefited 
from a previous interaction. In the other case, the agent should reciprocate because (2a) he will or (2a) may benefit in the future.

\begin{tabular}{|l|l|l|l|}
\hline & ascending & descending & double \\
\hline direct & & & $\mathrm{x}$ \\
\hline indirect & $\mathrm{x}$ & $\mathrm{x}$ & \\
\hline benefit in past & & $\mathrm{x}$ & $\mathrm{x}$ \\
\hline benefit in future & $\mathrm{x}$ & & \\
\hline
\end{tabular}

This distinction between past and future benefit helps us to further distinguish the three models: ascending reciprocity seems the most selfregarding as it relies on promises of future benefits for oneself. By contrast, descending and direct reciprocity point to what happened in the past as the reason for now owing reciprocation to the future. What is then special about descending reciprocity is that it justifies owing by reference to previous interactions but does not restrict the scope of the recipients of the past-generated obligation to those who benefited the obligated agent directly. It is thus the form of reciprocity closest to altruism. ${ }^{3}$ We blur the line between descending reciprocity and altruism even further the less we require the past interactions to be specific and equivalent as concerns the previous interaction and its content, and the more we generalize such past interactions to other people.

(ii) To say that reciprocity is 'generalized' (Arneson 1997; Page 2006; Kittay 1999) is to argue that (a) all agents are (necessarily) the recipients of gifts and benefits, in particular from preceding generations, and (b) all human beings, living and future, are worthy recipients of the obligation thereby generated. In other words, the obligation is generalized in two ways at once: with regard to (a) the obligated party and (b) the obligee. The first of these claims (a) can be justified in a number of ways: by reference to the care needed during infancy in order to become a mature adult (Held 1995; Kittay 1999); by reference to the role of language (Brandom 1994, 2000b; Habermas 1981, 1988; Heath 2001; 2003; 2008) and intersubjective relations of recognition (Honneth 1992) in the constitution of agential competencies; or by reference to phenomenological accounts of transcendental historicity (Heidegger 1962; Derrida 1978; Levinas 1969), according to which agency requires the precedence of a lifeworld to provide an agent with meaningful choices (cf. Taylor 2006; Habermas 1981). 
I cannot discuss these points in detail but take this as given for now: autonomous agency does not exist in a historical vacuum but emerges in response to and by assuming (that is, appropriating as one's own) benefits, from laws and institutions to languages and traditions. It is these kinds of argument that I think should be used to counter Brian Barry's objection to reciprocity as a model of justice: his claim that the mere fact of receiving an involuntary gift cannot by itself obligate (Barry 1989: 232, cf. Nozick 1974: 95; see Gosseries 2009 and Page 2007 for discussion of this point). The counterargument insists on the fact that the freedoms and abilities that make up an agent (including the very ones the agent needs to use to reject the obligations that otherwise come with gifts) could not have developed without accepting the gift.

The second claim (b) that I group under the heading of generalized reciprocity is rather controversial in the literature. According to this claim, the range of recipients is not limited to contributing members. This claim is of central importance to intergenerational justice, where it has been argued, precisely, that the lack of a two-way causal interaction between the present and a nonoverlapping future generation undermines reciprocity (Page 2006 calls this the 'non-reciprocity problem', the one that led Rawls to abandon the application of reciprocity to the problem of just savings). The generalization to all seems to undermine the basic intuition that may tempt one to buy into reciprocity as a model in the first place, namely the intuition that no one should free-ride on the efforts of others. ${ }^{4}$

I cannot discuss this issue in detail here but would like to say that the second generalization here may be seen as an extension of the project of 'indirecting' reciprocity. It is not so much that, in response to the problem of future people and the long-term disabled, we realize that we have to supplement justice as reciprocity with additional arguments that derive obligation now not from the reception of benefits, but from other people's vulnerability and need for care. These motifs are an undeniable part of moral relations, of course. Still, the reciprocity argument is largely independent of these concerns, it that it runs (roughly) as follows: All agents are the past (and even continuing) recipients of care and other agency-enabling benefits, so that all agents have reciprocity obligations. Reciprocity obligations, however, are indirect in that they may be, and often must be (as the donor is no longer alive, or for other, not yet normative reasons), discharged by giving to third parties. This may raise the expectation, but by no means the necessity, that the receiving party be able to reciprocate, or already reciprocated.

Hence, an agent has an obligation to reciprocate to a third party, whether or not that party has contributed or can be anticipated with certainty of 
contributing in the future. Given the unpredictability of the future and the fact that we cannot and should not seek to control it as much as we can, accepting indirect reciprocity amounts to accepting that future beneficiaries of present reciprocation need not themselves be contributing members. Lacking means of sanction, we may of course still expect indirect reciprocation of present and future recipients them in a normative sense, thus generating indefinite chains of obligations.

Once the object of the reciprocity obligation is indefinite, unpredictable, and uncontrollable, a crucial question is to whom we should reciprocate and in what ways, and this is where vulnerability, need, and equal interest, however rendered comparable, come in as the most obvious candidates. This does not make need, or equal interest, a secondary consideration; it just means these considerations often overlap with, but are not required for, the reciprocity obligation. When the two normative reasons overlap, they reinforce each other, but they remain independent reasons. In this sense, an indirect approach to futural obligations is quite compatible with a direct approach, one that views obligation as arising directly with the neediness or the equality of the other(s). Should the indirect obligation be too unspecific as concerns its object or its content, it may indeed invite a direct account.

The general idea of indirect reciprocity remains, however, that the material possessions and agential competencies of an agent, no matter how much of it is naturally endowed, do not simply belong to an agent as his or her property. Rather, given that they could not have become what they are without the contribution of preceding others, from education to tradition, these 'possessions' always already stand under the claim to share them with others who need their assistance. This, we might say, is what Lockean self-ownership tends to forget, however understandable as a grounding of negative rights to non-interference and bodily integrity. The claim to share is not superadded, as a supplement, to these possessions and competencies; rather, the claim is as deeply embedded in them, inasmuch as individualization is only possible as socialization (cf. Habermas 1988, 1983; Levinas 2000; Fritsch 2011, forthcoming).

(iii) The third feature of the model of reciprocity I wish to advance here is that it is asymmetrical (in the narrow sense, the wide sense including indirectness and generality). For while intergenerational reciprocity insists that sociality involves a long-term connectedness in both temporal directions, this long-term connectedness should not lead us to overlook that intergenerational responsibility essentially begins at home, as it were, in the living now, among contemporaries: namely, in the (overlapping) relation of those who give possibilities for living-on to others who may survive the donors, a relation most 
paradigmatic between adults and minors. Several aspects of this elemental focus on the asymmetrical relation in the here and now are worth highlighting.

(a) First, responsibility is what I would call 'capillary'. The long view of intergenerational justice, as recommended by reciprocity, should not abstract from the fact that both material and symbolic goods are no anonymous fund bequeathed by some collective entity called 'history' or 'the past' and in turn owed to 'future generations' (cf. Derrida 2002). Rather, past-derived and futuredirected responsibilities pass by way of specific people in specific circumstances, however mediated by institutional frameworks and collective entities (languages, traditions, memories, etc.).

That a responsible agent is singularly rooted in history further means that she cannot ever fully escape her own moral perspective. Taking the other's viewpoint may of course be viewed as an essential moral competence (cf. Habermas 1990), but as Iris Young pointed out, putting oneself in the other's shoes is not only impossible but fraught with the dangers of undetected distortion (Young 1997), in particular if we cannot actually converse with the other. We must avoid confusing an agent's viewpoint, at and as which she is called to act responsibly, with the moral point of view, in which abstractions, including from historical time, are taken into account in order to reach impartiality. The effort to assume an impartial moral standpoint above history, however necessary, is otherwise in danger of escaping the singular stand from which each of us must act for others. Faced with a drowning child, for instance, pointing to the other bystanders as equally called to responsibility from an impartial standpoint in no way lessens my duty. In the intergenerational setting, we may in particular not abstract from the temporal precedence that puts each one after others and before yet other others over which she has asymmetrical power (an asymmetry we will turn to shortly).

This is why it is important not to dissolve our intergenerational responsibilities into those of our 'generation', and to abstract from them further by holding this entity, our generation, responsible to other generations, often modeled as non-overlapping and so an indistinct 'future'. Rather, each agent singularly contributes to the future, in good or in bad ways, and if responsibility fundamentally requires letting the other live-and that means, potentially, letting her survive me-then each of us is obligated to care for the future.

The capillary nature of responsibility and the singular situatedness and contingent historicity of our lives should of course not lead us to overlook that, to determine what is impartially just, certain abstractions (in particular from the particularities of parties to be treated as equals) may be necessary-abstractions 
that, however, also need to be undone again and again, both in view of the objects and the subjects of moral concern (cf. Fritsch 2006, 2010). Nor should singularizing historicity lead us to forget that, precisely as a result of the fundamental relationship to the past on which intergenerational reciprocity insists, the indebtedness to the past is also a collective matter. For many of the debts in question are also shared as a result of the intrinsic commonality of language, tradition, memory, history, and institutions. These institutions include those of the nation-state that often, as a result of contingent events, happens to organize and coalesce the commonality of shared histories and languages even as states face a multicultural and polylinguistic citizenry. Recognizing both the singular and the shared aspect of historical indebtedness and futural responsibility need not contradict one another: in fact, climate change responsibilities, for instance, are typically thought of, and discussed and bargained internationally, as divided among countries rather than individuals, despite the fact that both the private and the public contributions of individuals are crucial.

(b) Second, the caution regarding abstraction from singularities also throws into relief the asymmetry and dependency of moral relations upon which we already had occasion to remark. It is an asymmetry easily overlooked even in the intergenerational setting by the otherwise understandable impulse to counter a positive discount rate with arguments for the equality of present and future persons.

For in the face of the 'social discount rate' frequently employed by economists and the common (perhaps anthropologically deep-seated) shouldershrugging regarding distant generations, the effort to ensure the equal treatment of the unborn is worthwhile and understandable. But it easily misses a fact of life: the power asymmetry (Barry 1989: 189, 246) between the generations that puts us the living into greater responsibility for future people than they could have for us. ${ }^{5}$ The effort to treat all generations impartially and equally should not lead us to abstract from the singular generational relations into which we are thrown, as if we could assume an Archimedean standpoint above the generations. And these singular relations often (if not always) feature a power asymmetry that is particularly characteristic of generational relations even among the living. For we must not underplay the role of different times in human relations: if some are necessarily born before others, then they will have to take more responsibility as a result of the greater power they have, in particular if, as is the case with humans, a new member needs intensive, singularizing care, lasting for about 15 years. At least during this time, the care-giver takes responsibility for the other, but not (or not to the same extent) vice-versa. Thus intergenerational connectedness implies that responsibility is not only or primarily among equals 
but first and foremost asymmetrical, involving a kind of taking turns: adults care for minors who in turn become the adults to care for the old and the new young. (This recognition is the main reason I speak of asymmetrical reciprocity rather than indirect reciprocity, as the standard literature does.)

(c) Third, the asymmetrical responsibility to care for those who survive us is not limited to overlapping (equally living) people, but stretches to distant future people in their very indefiniteness (as concerns number and identity). I believe this point to be crucial though easily overlooked. If responsibility is capillary and asymmetrical, then it also implies an 'infinite' element that relates to distant future people not so much directly, but via those who will survive through our care: responsibility for distant non-overlapping generations begins with the responsibility we take today for the next generation.

Responsibility is capillary, we said, in that it uncircumventably passes through singularities. And further, if an appropriate paradigm case of responsibility is that of an adult for a minor (or as well a teacher for a student, a trainer for a trainee), then responsibility includes responsibility for the responsibilities that the minor will have in the future but is not yet, or not yet fully, capable of understanding and exercising. (For instance, parents and teachers are, or should be, concerned about a child's success in school: so that the child be able in the future to take care of itself and its dependents.) When we take responsibility for another, we substitute ourselves for her in assuming, for now, her responsibilities for herself and for others. And if I seek to ensure in the here and now that my (metaphorical or biological) 'child' (my survivor) be able to take care of her 'children', then I must also seek to ensure that her children's children be able to do so with regard to their children, ad infinitum.

This infinity of responsibility seems perhaps especially counterintuitive if we assume rough equality between mature adults as our paradigm: why should I be responsible for, say, the gaming debts of another adult? While I think the infinity could be rendered less implausible in cases of adult-adult interactions as well, ${ }^{6}$ it may suffice here to point out that some of the crucial elements of the adult-minor relation, in which infinite responsibility seems more plausible, do apply much more widely, and in fact are central to the intergenerational case. I take these crucial elements to include, first, the fact that the other owes her existence and her life circumstances to me, and second, the asymmetry or dependency discussed above: the other cannot yet take care of herself but depends on us to enable him to do so in the future. Regarding the first, parents are never alone in causing a child to exist; society in general (including the work of its past) generates the conditions under which bringing into existence is decided upon and can be successfully carried out. Further, by contributing to 
society's cooperative scheme (including investments, savings, infrastructure, and so on) as well as to its institutions, tradition and culture in which the child grows, each member also contributes to the identity and the life circumstances that bring the child into existence as who she will be. This is of course relevant to the second element regarding the asymmetrical dependency of the minor on the adult, an asymmetry that we said generally holds with regard to future people. Here, our temporal precedence implies that we are called upon to enable those coming after us (overlapping and non-overlapping) to meet their responsibilities when they will have reached their time. As a result, each adult member of society, and not only parents, inherit an infinite responsibility.

Responsibility even for distant generations, then, begins-and begins again, in response to other such beginnings - in the relation between overlapping generations but from these singular circumstances it expands fast to include responsibility for many others, including those in the distant future. When an adult takes responsibility for a minor's future responsibility to yet other future people's responsibilities, we may speak, with Levinas, of a kind of 'substitution' (Levinas 1998) for the other's responsibility that also involves a moment of what he calls 'infinity' (Levinas 1969): Our responsibility for future people precedes their turn, but thereby also exceeds their responsibility. We must take responsibility not only for them before they can reciprocate but also for their responsibility to take responsibility for their (future) others, and so on-to infinity.

While responsibility is future-directed, the infinity stretches in both directions: neither in the future nor in the past can we trace all the capillary and substitutive connections of which we are the recipients as well as the addressees called on to take our turn. But the indefiniteness in both directions in no way lessens the responsibility of the present, for it remains the heir to the past and will engender the world of the future, always already in the process of becoming the ancestors for the future. If we want to take care of the long-term consequences of our actions, we have to now enable our 'children' (i.e., all those who will survive us) not to remain children. That is, we should enable them to discharge their responsibilities to the next (and subsequent) generation(s). As climate change issues demonstrate to us on a daily basis, we have the possibility of severely hampering, perhaps irretrievably, the means of future life to discharge its obligations to the next generation. To prevent this is thus a responsibility not in the first instance to nature itself, or to future people as a collective entity (or to humanity), but rather to the responsibility of the singular other to whom I give 'birth' (metaphorically or indeed biologically) and who may or will (some potentially and others in fact) survive my death. Responsibility passes by way of 
always singular (but paradigmatically dependent, not equal) others but from there expands fast to others to whom I am asked to give life as a new beginning. ${ }^{7}$

The point about infinity introduces the last section, in which I want to indicate some further features of this model that I think are attractive.

\section{Advantages of Intergenerational Reciprocity}

\section{(i) Motivation}

A perhaps obvious advantage of emphasizing the infinity of asymmetrical responsibility lies in relying on what was right about the early Rawls's intuition, later abandoned, that rational agents care about their descendants. ${ }^{8}$ The key point here is that most of those who belong to Becker's "tough crowd" (those strategic actors who need convincing to play by rules of justice in a cooperative scheme; see Becker 2005) accept the fact of close personal relations and duties to their offspring or to minors or dependents under their care, or simply to younger, less experienced people (from children to students and trainees, the disabled, and so on). My strategy here consists in building on this acceptance to show that nestled in this duty is an obligation to care for distant future others, not only despite but even precisely because of its indefiniteness, even its infinity. The psychology of this motivation to care for dependents may be combined and further strengthened by what psychologists call 'generativity' and the desire to live on symbolically: to stave off the meaninglessness of death by investing in projects that will outlive the investor (see Wade Benzoni 2009: 182ff., and the rich notion of 'fecundity' in Levinas 1969, then its elaboration in Guertler 2001 and Guenther 2006).

Psychological research may also recommend the emphasis on intergenerational reciprocity, in particular in its 'capillary' form, for another reason. Research has shown that one key factor that motivates people to care for the future is to realize the extent to which they themselves were provided for by preceding others. Wade-Benzoni claims that the egocentric bias in determining what is intergenerationally fair can best be overcome by increasing the understanding of the contributions to one's life circumstances made by predecessors. ${ }^{9}$ Part of the reason for this is the fact that, having already happened in all its detail, intergenerational indebtedness is more easily and concretely realized by reference to the past and the capillary responsibilities thereby generated. This brings me to the next advantage of reciprocity, among which we must count, then, avoiding the abstraction from the past and from concretely overlapping responsibilities to those who may survive us. 


\section{(ii) Problems with Intergenerational Abstractions}

The second advantage of asymmetrical reciprocity is negative in that it points to-and I can here indeed do no more than point to-the weaknesses of other approaches that reciprocity promises to handle better. By and large, reciprocity fares better in the face of many challenges specific to intergenerational justice because it accepts that sociality stretches across past and future generations. ${ }^{10}$ As indicated, the advantage of this kind of asymmetrical model is that we do not abstract from the actual social relations in which we are placed. On this model, we do not (or not primarily) assume a relation of the presently living (individual or generation) with the unborn in the (far, non-overlapping) future, to whom we are said to owe directly. (a) Such a relation with a non-existent object of moral concern appears to, as indicated, engender only weak motivating force unless it is supported by concrete accounts of predecessors' contributions to the present and the concern for the overlapping future generation.

(b) The direct model also plays its part in generating some well-known ontological problems, problems that basically lie in attributing rights, interests, or morally relevant harm to not yet existing people, people whose existence is further contingent on actions of the presently living. Among these, we find of course the non-identity problem (whose details I will not go into here; see Parfit 1984; Roberts and Wasserman 2010) and the well-known problem of attributing subjective rights to bearers who cannot (yet) exercise them, such as animals and future people (see note above).

(c) We may here also mention the worries, discussed above, about the abstractions of impartial equality and the difficulties (particularly strong in the case of aggregative theories) arising from the indefinite number of future people. For it has been suggested that it is unclear how we shall divide the intergenerational cake equally if we do not know how many recipients there will be (Lauwers \& Vallentyne 2004, cf. Gosseries 2009).

(d) Direct distributive approaches, on account of their abstractions from capillary connectedness, also tend to yield improbable problems, such as the problem, claimed to be serious for a Rawlsian approach, of the initial generation. Never being a recipient of cooperation over time, contracting parties under the veil of ignorance, so the argument goes, could not accept the unfair situation of the first generation (Gardiner in Gosseries \& Meyer 2009). But these problems occur only as a result of abstracting from the reality of being-born, i.e., of being thrown into following others who asymmetrically precede us. Supported further 
by the claim of the context-embeddedness and historicity of all meaning, this insight may lead one to deny the possibility of a 'first' generation (Derrida 1993; cf. Part Two, ms). Further problems result from the otherwise well-motivated and thus frequent modeling of the intergenerational problem in such a way as to abstract from overlap. In response, we should remember the fact that capillary and asymmetrical responsibility point to, namely, the fact that already the notion of 'a generation' is an abstraction: people are always born into and pass away in it, continuously blending one with another generation.

(e) In linking the temporal modalities (past, present, future) and the generations, intergenerational reciprocity may be in a better position than direct futural duties (those that ascribe moral standing directly to not-yet existing people) to capture widely accepted principles of international justice in the arena of environmental concerns. The principles I have in mind are all those that combine responsibilities in the past (such as polluter-pays principles) as well as present capacities with future-directed duties.

This combination may then further avoid the contentious (strategic?) division of responsibilities into those that can be associated with the past, the present, and the future (cf. e.g. Garvey 2008). If we conceive of duties to future people as the indirect result of what every present generation (even if largely involuntarily) received from its ancestors, then the resulting indirect futureoriented duties take into account, in the very grounding of the future orientation, how much a society benefited from past usages of a limited resource (such as the carbon-absorptive properties of the atmosphere) to calculate both present capacities and futural duties to address the problems resulting from such usages. ${ }^{11}$

By contrast to the abstractions of directness, the asymmetrical version of intergenerational reciprocity exploits the generational overlap and the human relationality across birth and death to argue for a doubly indirect relation to future people. It is doubly indirect in that duties to the non-overlapping future are generated by (dead or alive) ancestors and the living who will survive the agent. In both cases, however, the overlap with the preceding and with the following 'generation' already contains, as it were, the reference to the remote past and the distant future. Directness neglects mediation of our relation to future others by way of asymmetrical responsibility for intermediaries, and further that the present is always enabled by the past to do its share. ${ }^{12}$

(f) Now one may argue that direct theories, despite some of these problems, have one crucial advantage over reciprocity: they are more likely to be "demo-sensitive" in that they take the (expected) number of future people into 
account. For if one argues, for example as a luck egalitarian, that the current generation owes to future people equivalent opportunities for well-being as a direct result of these people's morally relevant interests, then a generation must transfer more goods to a larger generation than it chooses to bring about. By contrast, Gosseries (in Gosseries and Meyer, 2009) argues that descending reciprocity in particular, precisely because of its indirectness, is incapable of taking population size into account: reciprocity merely requires that a generation passes on as much as it received, regardless of the number of people it puts into the world. As a result, it may allow gradual impoverishment per head over time. ${ }^{13}$

In response, I remind the reader that I do not wish to rule out in general an account based on direct intergenerational relations, for as I said above, the reciprocity account is compatible with, and may even invite, a theory that roots moral obligation in the vulnerability or the equality of others. Nonetheless, it seems that this alleged defect results in part from abstracting from the generational overlap in which we found a capillary, asymmetrical, and infinite responsibility. For if I realize that (P1) I owe life chances to another (in part) because they were given to me, and I further understand that (P2) enacting this responsibility, in particular in those cases where the other owes his existence to my choices, requires enabling the other to meet his future responsibilities, and I also see that (P3) the other's future responsibilities will be crucially affected by the number of people to whom she is responsible, then (C) I must be concerned to limit the number of future people in view of these responsibilities.

(g) As the last point concerned, then, not only the question of why we owe future people, but what we owe them, this may be a good point to highlight the advantage that one may in fact see in the fact that intergenerational reciprocity both justifies future-oriented obligations and outlines their content.

A model of reciprocity addresses not only why we are obligated (namely because we are recipients who could not have become agents without the care and the gifts of preceding others), but who should respond in (roughly) what way to the obligation. And given that it combines responsibilities to the past with obligations to the future, it may help to address, in one swoop, two different questions concerning the content. For example, with regard to climate change, we may ask where we should set a total cap on GHG emissions. Reciprocity will respond that a generation can emit to the extent that it can pass on the atmosphere in at least as good a condition as it received it. As I said, this follows from the responsibility that comes with being an heir and thus a trustee, but also from the idea that we should take responsibility for the responsibilities of our overlapping survivors, so as to enable them to meet their likely future duties to, as well, yet other future others. 
The duty to seek to ensure the habitability of the planet for the indefinite future (for at least as many people as it can support now) may then be a (further) argument for a precautionary principle (see Gardiner 2006). ${ }^{14}$ Further, due to the past-orientation, the model can also say why this generation, to the extent it can, should also take responsibility for the harm that a warming atmosphere is already in the process of inflicting and will continue to cause due to past emissions.

The orientation to the past, then, may also help to address the second question related to the content, namely, how to share or divide the burden of reducing GHG emissions among countries so as to come in under the cap (cf. Gosseries 2005: 3). With respect to the latter question, a reciprocity-based approach would hold each country responsible not only for what the past gave it in terms of positive goods (among these, a habitable biosphere), but how much it already used of the available resources. The argument here is that the use, by ancestors, of the carbon-absorptive properties of the atmosphere, is intricately related to the developmental advantages of some countries over others. Hence, receiving and using what the past bequeathed by benefiting from these advantages engenders, ceterus paribus, differential duties with regard to action in the present for the sake of the (global) future.

\section{(iii) Overlap and Non-Overlap}

In talking of what recommends intergenerational reciprocity, in the form I have sketched it here, we should take account of its temporality, the temporality of a long view stretching in both directions. Throughout, the argument has been that indirect reciprocity best responds to the social-ontological connectedness of human life, and thus to social-historical time. The evolution of life, but also human culture, knowledge and technology, develop over a very long time, growing out of and with natural evolution and thus always in a natural environment that also undergoes very long-term changes, both natural and manmade. Intergenerational connectedness is a long-term connectedness, reflected in the noted indefiniteness in both directions. The intergenerational setting, with the special challenges of the absence of overlap as well as the reality of temporal precedence and the concomitant power asymmetries, merely foregrounds the temporal aspects of sociality in general. The familiar contrast between intra- and inter-generational justice may thus commit us to a false dichotomy.

But as indicated, this long view should not lead us to overlook the intergenerational relations embedded in the here and now. Human 
connectedness includes a crucial temporal moment, introduced into life by that which also separates us: birth and death. The dependencies, asymmetries, and unknowns generated by these facts of life crucially affect all social relations. To begin with, a moral agent has been born by another (literally and figuratively), thus demanding that we harmonize autonomy with dependency on a preceding other and equality with intergenerational power asymmetries as well as with different temporalities that make interpersonal comparisons of well-being difficult. At the same time, the mortality of the other first of all reveals the profundity of his or her vulnerability to possibly harmful change, to the point that we may say the command to let the other live is at the core of human relations as always already moral relations. Further, in its unpredictability and unknowability, death also points to the temporal alterity of the other: that the other's time is not mine means that she may survive me, so my gifts to her are destined to be future gifts.

The link between asymmetrical reciprocity and the natural-ontological constitution of time can be further explored by looking at what many see as one of the special challenges of intergenerational ethics, namely the absence of overlap (see Gosseries \& Meyer 2009: 3). Responsibility even for distant generations, I argued above, re-commences in the relation between overlapping generations. The asymmetry that thereby enters human relations as well as this continuous and discontinuous temporality require that we pay very close attention to the role of overlap in accounts of why and what we owe future people. As indicated, many theories abstract from overlap (so as to model the intergenerational problem in pure form; Gosseries in Gosseries \& Meyer 2009, Gardiner 2006b, etc.), others make it central to an account of futural obligation (Gauthier 1986, the early Rawls 1971). It is crucial to conceptualize this issue in the best possible way.

Overlap is important because, as we saw, responsibility even for distant generations is already referenced in asymmetrical care for those overlapping others who may and for those who will survive the presently responsible agent. We should not, I argued, abstract from these multiple mediations and their attendant responsibilities, as if the present had a 'direct' relation with nonoverlapping future people. But non-overlap, the discontinuity implied by a new generation, is also crucial. It would be problematic to stress the asymmetry in responsibility, and thus its infinity, without also anticipating that the 'minor' will become an adult who begins life anew. Giving chances for life to the other qua other (not killing, letting live) means precisely giving these possibilities in such a way that they become unassumable and uncontrollable by the donor. This implies that we do not overdetermine future others to the extent of denying their autonomy and their chance of a new beginning, a beginning that we should not 
think of as merely continuing our projects. ${ }^{15}$ To enable the future responsibility of the other requires enabling her to carry out her responsibilities, but not predetermining how she does so, let alone viewing her as merely carrying on the project of the species, as a mere vessel passing on human genes or a human heritage (cf. Guenther 2006).

In fact, one may argue that non-overlap, the lack of shared time, extends even to contemporaries. For what makes up the moral worth of persons is not wholly absorbed into objective time, the time of nature, from which each lifespan would be utterly accessible and comparable. This can be better understood if we realize that an entity can become the object of moral concern only if it is subject to unpredictable change: only such exposure, including the threat and the ultimate unknowability of death, makes an entity vulnerable. The individualizing exposure to death as to the most extreme form of utterly passive vulnerability, however, renders each person unique and to some extent inaccessible from an objective viewpoint. This inaccessibility is the complement to the ultimate inescapability of the first-person moral standpoint I stressed above. Despite all that we share, this inaccessibility or alterity implies that there remains a temporal non-overlap between us. The gulf that separates us, however, is crucial to the constitution of moral worth (cf. Levinas 1969; Fritsch 2011, forthcoming).

The relationships of life across birth and death, then, disallow a neat division of responsibility into the temporal modalities because the temporal connectedness (the overlap and its infinite relation to the distant other) is part of responsibility, and responsibility therefore always already intergenerational. Similarly, the non-overlap, the ultimate inaccessibility and alterity of the other, also belongs to responsibility, as does the fact that by letting the other live I give possibilities that in principle are unassumable by me and so survive me. These undeniable aspects of responsibility in general have a temporal dimension stretching from past to future, articulating the wide-spread intuition (often expressed in terms of 'mother nature' or 'god') that the currently living are part of something larger that began before them and will continue after them, without for all that in any way lessening the individual participant's responsibility in this larger process.

\section{Notes}

${ }^{1}$ Although I also agree with Becker 2005, who continues Hobbes's line by arguing that the disabled, for example, can indeed contribute, positively and 
negatively, to social life. McCormick 2009 extends this line of thinking to future people, thus contesting the claim that future people cannot reciprocate (what Page 2006 calls the non-reciprocity problem).

${ }^{2}$ One may object to this indirectness on the ground that the third party does not (yet) deserve the benefits of cooperation, as it is unclear whether they will become contributing members. Apart from the 'generalization' and the 'asymmetry' I go on to discuss, both of which are highly relevant to countering the objection, we may also point out that a non-deep view of identity over time (cf. Parfit 1984) renders in fact all reciprocity indirect. For each other is undergoing change over time, in part as a result of the very benefits received, so that we could never have a perfect case of direct reciprocity. Given the inevitability of change over time, the initial contributor and the final beneficiary cannot be identical to one another, as is quite clear in the case of pension schemes (with regard to which many a retiree hopes that her earlier self had been more like her in terms of spending habits!). Of course, this valuable point should not be pushed so far as to deny the distinctness of persons, a denial with which Rawls famously charged utilitarianism (Rawls 1971).

${ }^{3}$ In fact, it is customary in theoretical biology to speak of "reciprocal altruism" (for a recent overview, see Rutte \& Pfeiffer 2009). The fact that indirect reciprocity and altruism are close here may also help justify the reading of Levinasian motifs as involving a kind of reciprocity, despite Levinas's own misgivings about reciprocity (cf. Tomasky 2008; Paradiso 2007, and my Part One ms). This fact may also help to explain why many people, otherwise prone to object to freeriding on account of expectations of direct reciprocity and to interpret the requirements of justice egocentrically, accept altruistic motivations in the intergenerational case (see Wade-Benzoni 2009). Rawls also argues that reciprocity as a moral idea is situated between altruistic impartiality and the thought of mutual advantage (Rawls 2001: 76).

${ }^{4}$ See Rawls 1971, and Klosko 1989 on this point. This is why, for example, Rawls' reciprocity model denies those who cannot become contributing members over a lifetime, e.g. the congenitally impaired, the status of equals in his argument for justice as fairness (cf. Rawls 1971, Nussbaum 2006, Sen 2004, as cited in Silvers 2009), arguing that their claims to care and dignity need to be dealt with in a secondary way. I do not want to enter the fascinating literature on this topic, the friendly or unfriendly responses to Rawls ranging from Kittay's claim that the parties to the original position need to recognize that they could 
themselves be in need of asymmetrical care, via Sen's proposal to view the primary goods as capabilities, to Becker's argument that disabled people do contribute to meaningful collaboration, perhaps just not as materially as others (Becker 2005) and Nussbaum's claim that we need to abandon the standpoint of 'rough equality' altogether (Nussbaum 2006).

5 To be sure, recognizing the inherently equal moral worth of all human beings as objects of moral concern does not stand in the way of recognizing differential responsibilities on the part of the subjects, the agents of moral concern called upon to act in response. Still, if we take moral and political relations among equals as our paradigm for a theory of justice, the importance of the normative asymmetry connected to the factual power asymmetry is easily overlooked. As I go on to argue in the text, the normative asymmetry implies responsibility for the responsibilities of the object of moral concern.-The power asymmetry is also crucial to the famous 'non-identity problem', which occurs because the present willy-nilly affects the identity of the future. Hence, an adequate response to this problem would have to countenance and develop the asymmetry.

${ }^{6}$ In fact, we might go so far as to say that moral relations always display a kind asymmetry that may or not involve a power asymmetry. Emmanuel Levinas argues that all moral relations, including those of mature adults, are characterized by a power and a related normative asymmetry: each has the power to rob the other of life chances, a power that for him makes the prohibition "Do not kill" the basic rule of morality. Given that the possibility of killing makes the other dependent on me, ethics in general displays a fundamental asymmetry between ego and alter (Fritsch 2011, forthcoming), an asymmetry that stands out in the intergenerational setting, for the present decides on letting future others live or not. Further, each person is singularly rooted in history and so cannot ever fully escape his own perspective, rendering his effort to assume an impartial moral standpoint, however necessary, in danger of escaping his responsibilities toward the other. As I read Levinas, the asymmetry and the inescapability account for the infinity of responsibility: in the face-to-face, I am supposed to realize that "I always have, myself, one responsibility more than anyone else, since I am responsible, in addition, for [the other's] responsibility" (Levinas 1989: 225f.).

${ }^{7}$ Even if we avoid hasty generalizations and exaggerations, it may be worrying in this context, not only for the next generation but also for distant ones, that there appears to be sociological evidence for the claim according to which 
consumerism tends to overturn the asymmetrical relation between adult and minor (cf. Barber 2007; Stiegler 2010). If the present generation is a spending one compared to the "saving" generation of the post-WW II era, 'infantilized' (Baudrillard) by its short-term relation to desire and its overdrawn credit cards, the debts-both monetary and in terms of failed responsibility to act on, for instance, environmental degradation-are passed on to the next. It is not only the natural though man-made givens of climate change, then, that tell us that we may be close to a critical point. In the chain of obligation, the problems generated by a generation failing to do its share are iterative: not only does the next then have even less resources and less time to do its part (cf. Gardiner 2006 a, b; Gosseries 2009), but it may also be less capable psychologically or mentally to take responsibility (especially for minors).

8 In Rawls, however, the intuition was perhaps ill articulated, for to respond to the obvious question what the self-regarding rationality of a party choosing under the veil of ignorance has to do with the other-regarding care for one's offspring's well-being beyond one's death, he made the contracting parties "heads of households" (Rawls 1971), thereby raising many feminist concerns as well as others, such as that the solution is ad hoc as the other-regarding motivation is introduced just to ground futural duties (Paden 1997). Wall adds another counterargument against the argument in the Theory of Justice: "Fair terms of association, not relations of love or concern, should determine the content of the just saving principle" (Wall 2003: 81). While I do not wish to base just institutions on love, my emphasis on the capillary nature of responsibility suggests we do not neglect the role of singular relationships, however mediated by institutional frameworks. There is widespread discussion surrounding the relationship between (universal and egalitarian) justice and care; for a start, see the papers collected in Held 1995. See also Menke 2004, Habermas 2003.

9 "Here, we suggest two potential avenues for enhancing intergenerational identification (and, consequently, intergenerational affinity and beneficence): emphasizing the role of past generations in producing present group identity and focusing on long-term group goals. First, theorists have argued that understandings of the past can have a powerful effect on feelings about the future (Sherif 1966). In intergenerational contexts, feeling identified with past generations may be more readily facilitated than directly enhancing identification with future others because past generations are more readily identified and specified. In addition, the role that members of past generations have played in creating the present group context makes the connection between past and 
present more easily clarified than the connection between the present and the future" (Wade-Benzoni 2009: 172; on the role of historical indebtedness in political motivation, see also Fritsch 2005). The second avenue Wade-Benzoni mentions lies in establishing long-term group goals that can only be realized by future people. As I argued, the stress on identification with continuing groups should be balanced and supplemented with stress on the singular, capillary pathways connecting each person with past and future.

${ }^{10}$ Allow me summarize these challenges here. The challenges that distinguish inter- from intragenerational justice include: (a) the absence of overlap between the parties, questioning whether we may assume a shared time, for example for purposes of measuring equal shares, among the living; the absence of overlap gives rise to, among others, the non-reciprocity argument, which holds that because there can be no mutually advantageous interaction between present and future generations, the present has no or few obligations to the future (Beckman and Page 2008, Page 2007), as well as the argument from temporal complexity, according to which duties to the future are hampered by the fact that both causal responsibility for harm and the effects of present actions stretch across generations in such a way that the agents bearing the duties are difficult identify (Garvey 2008: 59ff.) and caught in a particularly vicious collective action problem (Gardiner 2006); (b) the remoteness in time that has led to the uncertainty argument, according to which we do not know enough about the effects of our actions on future generations, in particular distant ones, nor enough about their needs, which might be radically altered by as yet unknown technologies (Garvey 2008: 90ff.; Routley \& Routley 1979) as well as the incommensurability argument, which suggests that the notion of justice itself may undergo possibly radical change, so that our current concept is inapplicable to future people (Ball 1985); (c) the non-existence challenge that leads to the argument from the unidentifiability of interests, according to which there can be no individual (at most, collective or generational) rights where they are not backed by identifiable interests (Weiss 1989), interests that rights-holders must be able to in principle defend themselves (Pogge 1995; Feinberg 1970), at least on a choice-conception of subjective rights (Steiner \& Vallentyne in Gosseries \& Meyer 2009); (d) the indefinite number of future people, an indefiniteness or infinity that poses great challenges for all aggregative theories of distributive justice that seek to divide the intergenerational cake equally; and (e) the nonidentity problem (Kavka 1981; Parfit 1984: 351ff.; Woodward 1986; Page 2006: $132 \mathrm{ff}$.), of which it is generally agreed that it acts as the persistent shadow from which all work on future duties seeks to emerge (Humphrey 2009; Roberts \& 
Wasserman 2010). The argument suggests that because the existence and identity of future individuals is contingent upon the actions and decisions of the currently living - thus highlighting another challenge, (f) the power asymmetry between the present the future (Barry 1989b: 189, 246)—even actions that arguably harm them, such as increases in $\mathrm{CO}_{2}$ emissions, contribute (if only indirectly) to their very existence; as a result, future people are not in a position to complain of these actions as they would have otherwise never existed at all.

The recent and (rapidly expanding) literature shows that most existing ethical theories, inasmuch as they subscribe to the person-affecting view that what is morally wrong must be wrong for an identifiable someone, cannot solve the problem of non-identity in particular (Page 2007; Heyd in Roberts \& Wasserman 2010), which is why many approaches ignore it as a merely technical problem with no consequences for policy (Tremmel 2009, 2010). The one ethical theory that, as Rawls famously argued of utilitarianism, disregards the distinct identity of individuals (Rawls 1971), and thus may be (though often is not) cast in impersonal consequentialist terms that evaluate action outcomes without reference to how they affect identifiable persons, fails on another score: it leads to the implausible view (the so-called 'repugnant conclusion') that, to increase overall (i.e., non-person specific) happiness, it would be morally advisable to generate as many future individuals as we can (Parfit 1984: 381ff.).

Of course I do not claim here that asymmetrical reciprocity has an answer to all of these formidable challenges. I only wish to indicate that it may open up fruitful lines of response.

${ }^{11}$ As we know, at the climate change negotiations in Copenhagen in December 2009, India and China accused industrialized countries of shirking the additional burdens that past emissions generate, that is, of not taking responsibility for having benefited from past emissions.

${ }^{12}$ One may argue that the "chain of obligation" model has a special problem, for as we all know, a weak link can break the entire chain: should a preceding generation fail to do its part, does this lessen or increase the responsibilities of the successor to care for its descendants? One may say that we are in this position, and, in part due to the longevity of GHG in the atmosphere, we are most likely putting the next generation in an even worse position when it comes to climate change. But as abstractions work for theoretical purposes only, and generations will always depend on each other, this is a real problem for any theory of intergenerational justice. 
13 "[T] he logic of reciprocity [on the 'narrow' version assumed here] consists in getting rid of one's debts, regardless of how many people will be led to benefit from it. If I give back as much as what I received, this will suffice to exhaust or cancel out my obligations, even if it means that, in case of population growth, a larger number of people will have to share the same amount of resources. The latter conclusion is problematic, for it would allow, in full compliance with this definition of justice, in the context of a model of descending reciprocity, for a gradual impoverishment per head, as new generations come on board. This problem is often overlooked by those who consider reciprocity-based theories of intergenerational justice as intuitively attractive" (Gosseries in Gosseries \& Meyer 2009: 138f.).

${ }^{14}$ However, when it comes to other questions that require a more precise tabulation, e.g. savings or investment rates, then we may need the supplement of direct approaches, as indicated above: reciprocity, of the indirect and descending kind, may not yield duties sufficiently fine-grained to address such issues.

15 This is a notoriously crucial issue for Thomas Jefferson's thoughts on constitutions. He argued at some point that they should be ratified anew by each new generation: "Every constitution, then, and every law, naturally expires at the end of 19 years. If it be enforced longer, it is an act of force, and not of right." This and further Jefferson references at: http://www.conlaw.org/IntergenerationalII-2-9.htm; see also Gosseries 2008b. 